\title{
Design of Solid State Transformer
}

\author{
P Yogananda Reddy \\ Department of Electrical and Electronics Engineering \\ $V R$ Siddhartha Engineering College, Vijayawada, India \\ R Giridhar Balakrishna \\ Department of Electrical and Electronics Engineering \\ $V R$ Siddhartha Engineering College, Vijayawada, India \\ M L N Vital \\ Department of Electrical and Electronics Engineering \\ $V R$ Siddhartha Engineering College, Vijayawada, India
}

\begin{abstract}
The present widely used conventional (or traditional) Line (or Low) Frequency (50 / 60 Hz) Transformers (LFT) have some merits like relatively economical, highly reliable and quite efficient but they suffer with certain drawbacks like sensitive to harmonics, voltage drop under load, no protection from system disruptions and overloads, poor performance under dc-offset load unbalances and no power factor improvement. As conventional transformers with copper wound wires on an iron core will not respond to a control signal as power generation becomes distributed and intermittent, we need electronic based regulated power supply with software based remote intelligence. Also to easily connect the new energy sources to the grid and to improve the power quality by harmonic filtering, voltage sag correction and highly dynamic control of the power flow, a new type of transformers based on Power Electronics, known as Solid State Transformer(SST) or Power Electronic Transformer (PET), has been introduced, which realizes voltage transformation, galvanic isolation, and power quality improvements such as instantaneous voltage regulation, voltage sag compensation and power factor correction. It is a collection of high-powered semiconductor components, High Frequency (HF) Power Transformers and control circuitry which is used to provide a high level of flexible control to power distribution networks. The SST provides a fundamentally different and more complete approach in transformer design by using power electronics on the primary and secondary sides of the transformer.
\end{abstract}

In this work, an attempt has been made to review the available literature on design of transformer at different frequencies, incorporation of power electronic devices (PED) like rectifiers and inverters and integrating them to design an economically viable and energy efficient SST.

Keywords: Solid State Transformer, Power Electronic Transformer, Harmonics and MAT Lab

\section{INTRODUCTION}

There has been a lot of talk in the past few years about coming up with a Solid State Version of Distribution Transformer. As we know, transformers are the essential elements of the power grid; they convert the high-voltage electricity delivered by power lines to the required level needed for consumers and vice-versa at generating stations. Transformers are widely used in electric power system to perform the primary functions, such as voltage transformation and isolation. They are one of the heaviest and most expensive devices in an electrical system because of the large iron cores and heavy copper windings in the composition. The term solidstate transformer (SST) is something of a misnomer because it is not a transformer in the traditional sense. It is a collection of high-powered semiconductor components, High Frequency (HF) Power Transformers and control circuitry which is used to provide a high level of flexible control to power distribution networks. With the evolution of power electronics and due importance of renewable power generation; present power grid is appearing as shown in figure-1 and hence the name "Smart Grid" accords with it. 


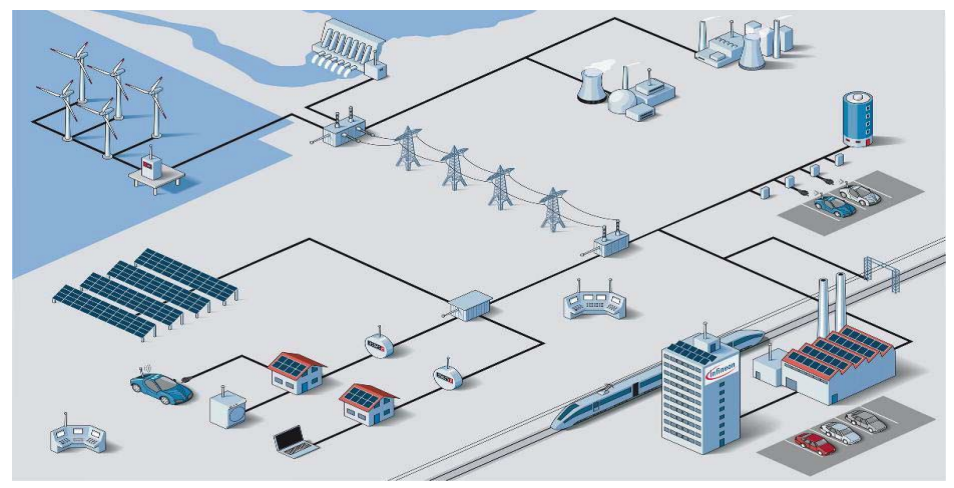

Fig 1. Present Smart Grid

\section{A. Field of invention:}

The present paper relates generally to electrical transformers, and more particularly to a solid state distribution transformer. Distribution transformers range widely in power delivery capability and physical size. Ratings are as small as $1.5 \mathrm{kVA}$ and as large as $500 \mathrm{kVA}$ or up to `small power` ratings of 2500 or $3000 \mathrm{kVA}$. The function of a distribution transformer is to reduce voltage on the medium utility system of from 2400 to 35000 down to utilization voltages of from 120 to 600 volts.

Transformers may be single phase devices or may be three phase devices, or may consist of single phase devices interconnected to supply three phase power. Distribution transformers can be oil-immersed, to provide better insulation and cooling or may be "dry-types" which are air-cooled, but will therefore be physically larger and require more weather protection than sealed, oil-immersed transformers.

Transformers generally contain two or more electrical circuits, primary and secondary windings, consisting of multi turn coils of electrical conductors that are interlinked by means of one or more magnetic circuits or cores. Cores typically consist of a plurality of ferromagnetic laminations that are stacked together to form a closed loop, surrounding and coupling magnetically the primary and secondary windings. Cores may be manufactured either from mutually overlapping or abutting individual laminations or from a continuous strip of magnetic sheet material wound around a mandrel to form a closed circuit. The magnetic and electric circuits are combined either by assembling the cores around pre-wound primary and secondary coils or by winding the conductor coils around one or more legs of the closed magnetic circuit.

Conventional distribution transformers suffer from several undesirable characteristics:

1) They may require mineral oil or other liquid for cooling and as a dielectric medium or may require ventilation to the ambient air for cooling;

2) The output voltage is a function of the input voltage and output current, and there is no provision to regulate the voltage or to compensate for power quality problems such as load harmonics, power factor or DC offset; and

3) Losses associated with energization of the core are present at all times and are independent of load. Efficiencies will approach zero for very small loads and will peak when supplying about $50 \%$ of nameplate rating. Lightly loaded transformers, therefore, are very inefficient.

The above-mentioned limitations of a conventional transformer may play a crucial role when power quality is in the balance.

Power transformer designs minimize weight and cost based on three assumptions:

(1) The power source is a sine wave,

(2) The frequency is fixed, and

(3) The voltage will not exceed a specified maximum.

This doesn't mean that the transformer has to be picky about how it is applied, but it does mean that proper attention is required if the assumptions are changed. In order to reduce the emission of greenhouse gas and supplant the limited energy sources like coal, oil or uranium, the number of renewable energy sources is 
constantly growing. All these points lead to have a best solution which was the reason for evolution of SST whose basic concept is shown in figure- 2 .

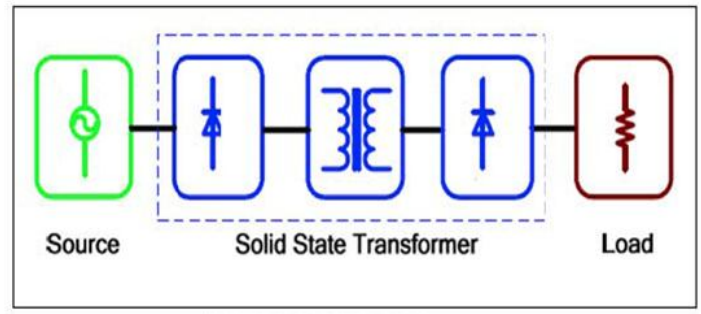

Fig 2 Basic Idea of SST

This development results in a rising number of distributed power plants, which are principally subjected to substantial energy fluctuations. SST's are the most effective conduit to connect the new energy sources to the grid and improve the power quality.

\section{B. Objective}

The SST provides a fundamentally different and more complete approach in transformer design by using power electronics on the primary and secondary sides of the transformer.

The objective of this work is as follows:

- Review of literature to find out the best topology for SST.

- Design of SST in MAT lab/Simulink.

- Design of High Frequency Transformer initially in the standard way and then development of a spread sheet for easy design and simulation for different scenarios.

- $\quad$ Purchase of raw material / components for the project and fabrication of SST.

- $\quad$ Testing the SST on load and tabulation of results.

- Result analysis and conclusion for an optimized solution.

\section{THEORY AND DESIGN OF TRANSFORMER}

\section{A. Design of Transformer:}

Brief specifications of transformer required for hardware implementation:

Table 1. Specifications of transformer

\begin{tabular}{|c|c|c|}
\hline S.No. & Parameter & Value \\
\hline 1 & Output & 100 VA \\
\hline 2 & Voltage & V1/V2: 440 V / 220 V without tap \\
\hline 3 & Number of phases & Single \\
\hline 4 & Rating & Continuous \\
\hline 5 & Cooling & Natural \\
\hline 6 & Type & Shell, distribution \\
\hline
\end{tabular}

\section{B. Design Calculations (100 VA, $50 \mathrm{~Hz})$}

The basic design procedure of transformer is followed as explained in the reference books [9]-[12],[13].

Output required : $100 \mathrm{VA}, 220 \mathrm{~V}, 50 \mathrm{~Hz}, 1 \mathrm{ph}$

Input available : $440 \mathrm{~V}, 50 \mathrm{~Hz}, 1 \mathrm{ph}$

Core : Shell type (E-I laminations)

Table 2. Assumptions for the design procedure

\begin{tabular}{|c|c|}
\hline Assumptions: & \\
\hline Max. flux density $(\mathrm{Bm})$ & $1 \mathrm{~Wb} / \mathrm{m}^{2}$ \\
\hline Current density $(\mathrm{J})$ & $3.5 \mathrm{~A} / \mathrm{m}^{2}$ \\
\hline Factor K (in E=K $\sqrt{\mathrm{Q})}$ & 0.8 \\
\hline
\end{tabular}




\begin{tabular}{|c|c|}
\hline Window space factor & 0.3 \\
\hline Core stack factor & 0.95 \\
\hline Voltage regulation & $+5 \%$ \\
\hline
\end{tabular}

Table 3. Constants used in the design

\begin{tabular}{|c|c|}
\hline Constants: & \\
\hline Resistivity of copper $(\rho)$ at $20^{0} \mathrm{C}$ & $0.017 \Omega-\mathrm{m}$ \\
\hline Density of iron & $7.70 \mathrm{~g} / \mathrm{cc}$ \\
\hline Density of copper & $8.93 \mathrm{~g} / \mathrm{cc}$ \\
\hline Specific iron loss & $1 \mathrm{~W} / \mathrm{Kg}$ \\
\hline
\end{tabular}

\section{Market price:}

Transformer grade iron $=$ Rs. $120 / \mathrm{Kg}$

Electrolytic copper $\quad=$ Rs. $600 / \mathrm{Kg}$

\section{Design:}

EMF per turn, $\mathrm{Et}=\mathrm{K} \sqrt{\mathrm{Q}}=0.8 \sqrt{ } 0.1=0.253$

Also, $\mathrm{Et}=4.44 \mathrm{Bm} \mathrm{f} \mathrm{Ai}$

$0.253=4.44 * 1 * 50 * \mathrm{Ai}$

$\therefore$ Net core area, $\mathrm{Ai}=0.253 * 4.44 * 1 * 50=11.396 \mathrm{~cm}^{2}$

Gross core area, Agi $=\mathrm{Ai} * \mathrm{Ks}=11.3 * 960.95=11.996$

$$
\cong 12 \mathrm{~cm}^{2} \cong 1200 \mathrm{~mm}^{2}
$$

$\therefore$ Use a core of either square section of size $\sqrt{ } 1200=34.6 \mathrm{~mm}^{2}$

(Or) rectangular section of size $32 * 38 \mathrm{~mm}$ as available in market.

Here, a rectangular core is preferred for construction.

$\therefore$ Adjusted core size is $\mathrm{Ai}=32 * 38=1216 \mathrm{~mm}^{2}$

New $\mathrm{Et}=4.44 * 1 * 50 * 0.001216=0.27$

Secondary current, $\mathrm{I} 2=100 \mathrm{VA} / 220 \mathrm{~V}=0.46 \mathrm{~A}$

Primary current, $\mathrm{I} 1=100 \mathrm{VA} / 440 \mathrm{~V} * 1.05=0.24 \mathrm{~A}$ ( $5 \%$ extra for losses)

Cross section area of primary conductor, $\mathrm{A} 1=\mathrm{I} 1 * \mathrm{~J}=0.23 * 3.5$

Dia. of primary conductor, $\mathrm{d} 1=\sqrt{ } 4 * 0.07 * \pi=0.3 \mathrm{~mm}$ (bare)

$$
\begin{aligned}
& =0.686 \mathrm{~mm}^{2} \\
& \cong 0.7 \mathrm{~mm}^{2}
\end{aligned}
$$

$$
=0.3+0.01=0.31 \mathrm{~mm} \text { (with enamel insulation) }
$$

Cross section area of secondary conductor, A2 $=\mathrm{I} 2 * \mathrm{~J}=0.46 * 3.5=0.13 \mathrm{~mm}^{2}$

Dia. of secondary conductor, $\mathrm{d} 2=\sqrt{ } 4 * 0.13 * \pi=0.41 \mathrm{~mm}$ (bare)

$$
\begin{aligned}
& =0.41+0.01 \\
& =0.42 \mathrm{~mm} \text { (with enamel insulation) }
\end{aligned}
$$

Primary winding turns, N1 $=\mathrm{V} 1 * \mathrm{Et}=440 * 0.27=1630$

Secondary winding turns, N2 $=\mathrm{V} 2 * \mathrm{Et}^{*} 1.05$

$$
\begin{aligned}
& =220 * 1.05 * 0.27 \\
& =856(5 \% \text { extra for voltage drop })
\end{aligned}
$$

\section{Core dimensions:}

Central leg width, $\mathrm{Tw}=32 \mathrm{~mm}$

Core stack height, $\mathrm{Hs}=38 \mathrm{~mm}$

Width of 'I' section $=\mathrm{Tw} / 2=16 \mathrm{~mm}$

Overall width, $\mathrm{W}=3 * \mathrm{Tw}=96 \mathrm{~mm}$

Length of ' $\mathrm{E}$ ' section, $\mathrm{L}=5^{*} \mathrm{Tw} / 2=80 \mathrm{~mm}$ 
Width of window, $\mathrm{Ww}=\mathrm{Tw} / 2=16 \mathrm{~mm}$

Length of window, $\mathrm{Lw}=1.5 * \mathrm{Tw}=48 \mathrm{~mm}$

Core stamping selected $=\mathrm{M} 4(0.27 \mathrm{~mm})$

No. of clamping's required $=\mathrm{Hs} /($ thickness of each lamination $)=38 / 0.27=141$

No. of E's required $=73$ and I's $=68$

Weight of iron $=$ total -2 windows $=[(9.6 * 8 * 3.8)-2(1.6 * 4.8)] * 7.7$

$$
=1800 \mathrm{~g}=1.8 \mathrm{Kg}
$$

$\therefore \quad$ Iron loss $=1.8 * 1=1.8 \mathrm{w}$

\section{Bobbin:}

Thickness $=2 \mathrm{~mm}$

Size $=60 * 48 * 70 \mathrm{~mm}$

\section{Window arrangement:}

Length of mean turn, $\mathrm{Lmt}=2(\mathrm{Tw}+\mathrm{Hs})+\pi \mathrm{h}$

$$
\begin{aligned}
& (\text { where } \mathrm{h}=\text { height } \text { of winding }=\mathrm{Tw} / 2) \\
=2(32+38)+\pi(32 / 2) & \\
= & 190.3 \mathrm{~mm} \\
= & 0.1903 \mathrm{~m}
\end{aligned}
$$

Length of primary winding, $\mathrm{L} 1=\mathrm{N} 1 * \mathrm{Lmt}$

$$
\begin{aligned}
& =310 \mathrm{~m} \\
& =31000 \mathrm{~cm}
\end{aligned}
$$

Length of secondary winding, $\mathrm{L} 2=\mathrm{N} 2 * \mathrm{Lmt}$

$$
\begin{aligned}
& =856 * 0.1903 \\
& =163 \mathrm{~m} \\
& =16300 \mathrm{~cm}
\end{aligned}
$$

Weight of copper $=$ volume of copper $*$ specific copper density

$$
\begin{aligned}
& =8.93 *[(31000 * 0.0007)+(16300 * 0.0013)] \\
& =383 \mathrm{gm} \\
& \cong 390 \mathrm{gm}(\text { considering lead connection to pri \& sec })
\end{aligned}
$$

Resistance of primary winding, $\mathrm{R} 1=\rho l / a 1$

$$
\begin{aligned}
& =0.017 * 310 / 0.07 \\
& =75 \Omega
\end{aligned}
$$

Resistance of secondary winding, R2= $\rho l / a 2$

$$
\begin{aligned}
& =0.017 * 163 / 0.13 \\
& =21.5 \Omega
\end{aligned}
$$

Voltage drop (sec.) $=\mathrm{I} 2 * \mathrm{R} 2$

$$
\begin{aligned}
& =0.46 * 21.5 \\
& =9.89 \mathrm{~V}
\end{aligned}
$$

Copper loss, $\mathrm{Wc}=\mathrm{I}^{2} * \mathrm{R} 1+\mathrm{I} 2^{2} * \mathrm{R} 2$ 


$$
\begin{aligned}
& =0.24 * 75+.46 * 21.5 \\
& =8.9 \mathrm{~W}
\end{aligned}
$$

Total loss $=$ copper loss + iron loss $=10.7 \mathrm{~W}$

$$
\cong 11 \mathrm{~W}
$$

Total weight $=$ iron weight + copper weight + misc. like insulation, clamps

$$
\begin{aligned}
& =1800+390+100 \\
& =2290 \mathrm{~g} \\
& \cong 2.3 \mathrm{Kg}
\end{aligned}
$$

Input $(\mathrm{S} 1)=$ output $(\mathrm{S} 2)+$ losses

$$
=100+11=111 \mathrm{VA}
$$

Apparent efficiency, $\eta_{=\mathrm{S} 2 / \mathrm{S} 1 * 100=90.09 \cong \mathbf{9 0 \%}}$

Cost of transformer $=$ cost of iron + copper

$$
\begin{aligned}
& =1.8 * 120+0.39 * 600 \\
& =\text { Rs. } 450
\end{aligned}
$$

Cost of insulation, clamps, bobbin $=25 \%$ of iron $\&$ copper cost $=$ Rs. 110

Cost of man power $=$ one person per half day $=$ Rs.200 (approx.)

$\therefore$ Total cost of transformer $=450+110+200=$ Rs. 760

\section{A. Simulink Model}

\section{IMPLEMENTATION}

A MATLAB/SIMULINK model of the proposed solid state transformer is realized. The three stage topology, as mentioned in 2.2.3, is chosen for the implementation.

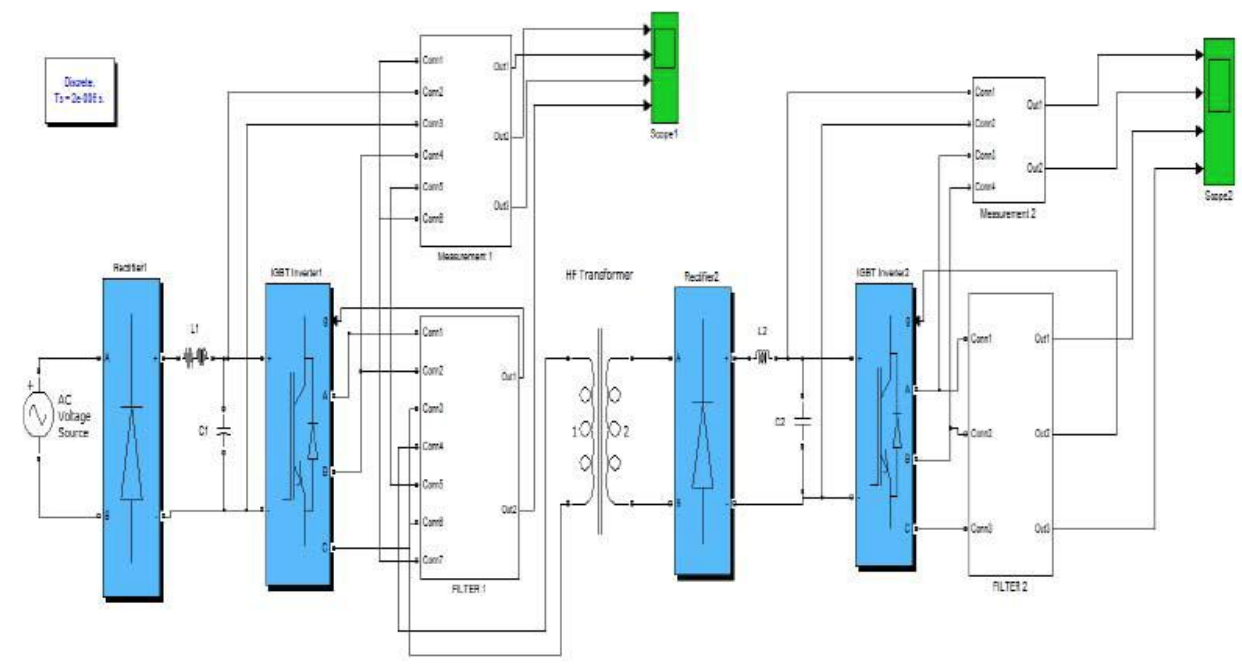

Fig 3.Three Stage topology of Transformer

\section{i. Operation of the model}

The input is an AC source of $440 \mathrm{Vrms}$ (622 Vpeak) with $50 \mathrm{~Hz}$ frequency supplying input to the rectifier 1 . Rectifier 1 is a single phase bridge rectifier with RLC filter. A very small resistance of $0.1 \Omega$ in series with an inductor of $14 \mathrm{mH}$ along with a capacitor of $4.9 \mathrm{mF}$ form the rectifier filter; rectifies the input sine wave to DC which will be the input to inverter 1 . The inverter is an IGBT version with LC filter. 
The frequency of the operation of the transformer depends on the working frequency of the inverter i.e. the triggering of gate pulse given to the IGBT. The inverter derives the DC supply and produces a 434 Vrms sine and is fed to the transformer. The transformer with a transformation ratio of 1:2 gives out $217 \mathrm{~V}$ rms to the rectifier 2 .

The same conversion technique, as the primary side, is carried on to get the final output of $220 \mathrm{~V} \mathrm{rms}$ (309.6 V peak) with a total harmonic distortion (THDv) of $1.56 \%$. The same model is simulated for the transformer operation at $50 \mathrm{~Hz}$ and $100 \mathrm{~Hz}$ and the plots are shown:

ii. Transformer operating at $50 \mathrm{~Hz}$

Transformer Input

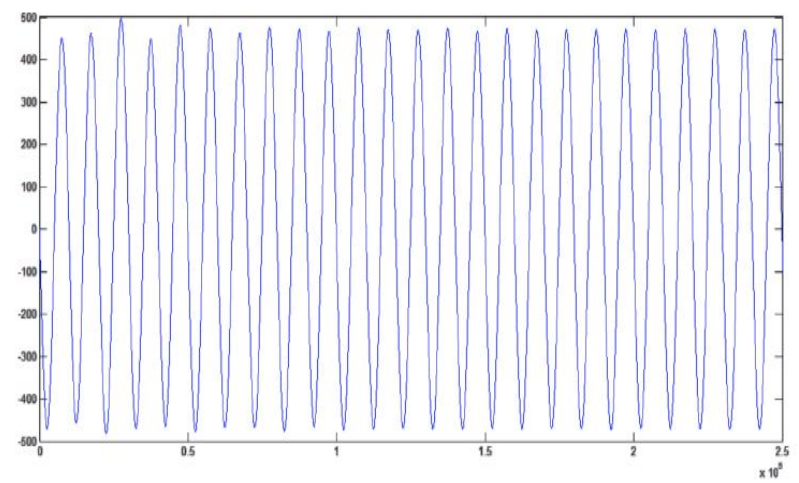

Fig 4 Transformer Input or Inverter 1 Output

\section{Rectifier 2}

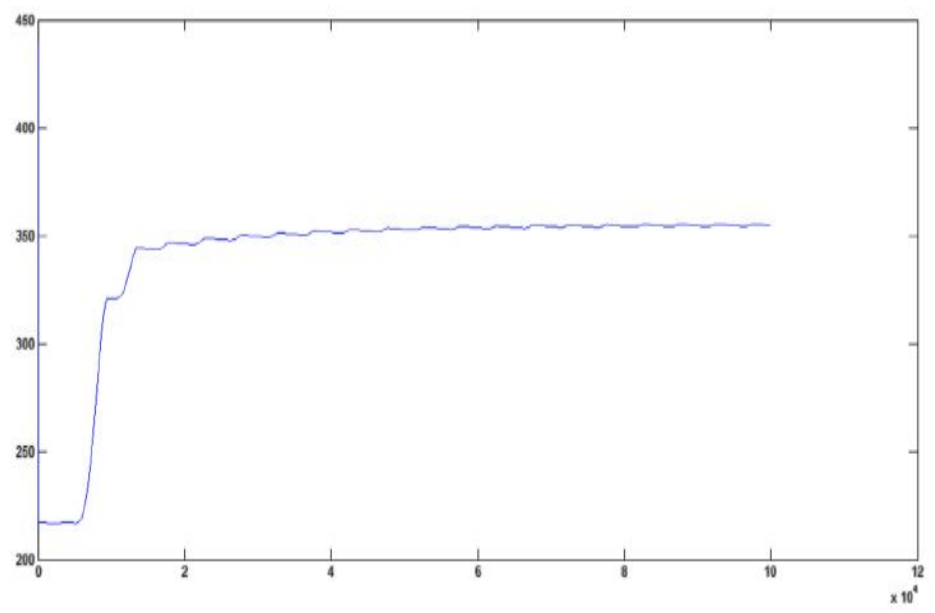

Fig 5 Rectifier 2 output or Inverter 2 output

\section{Final Output:}

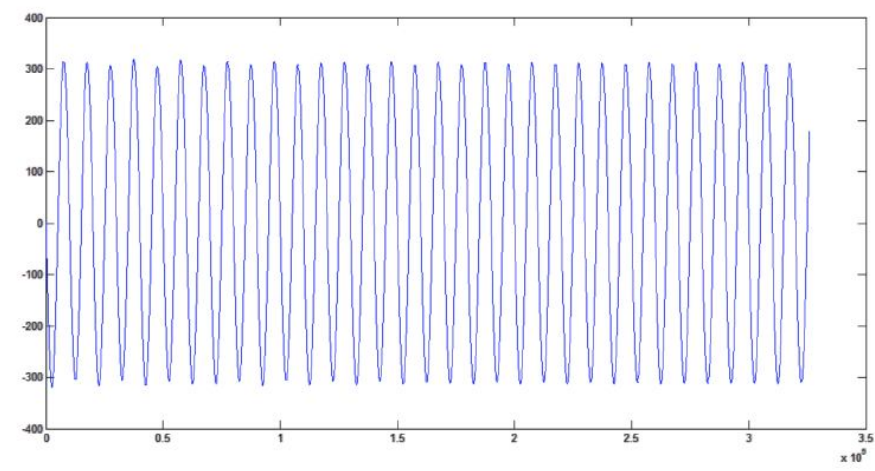




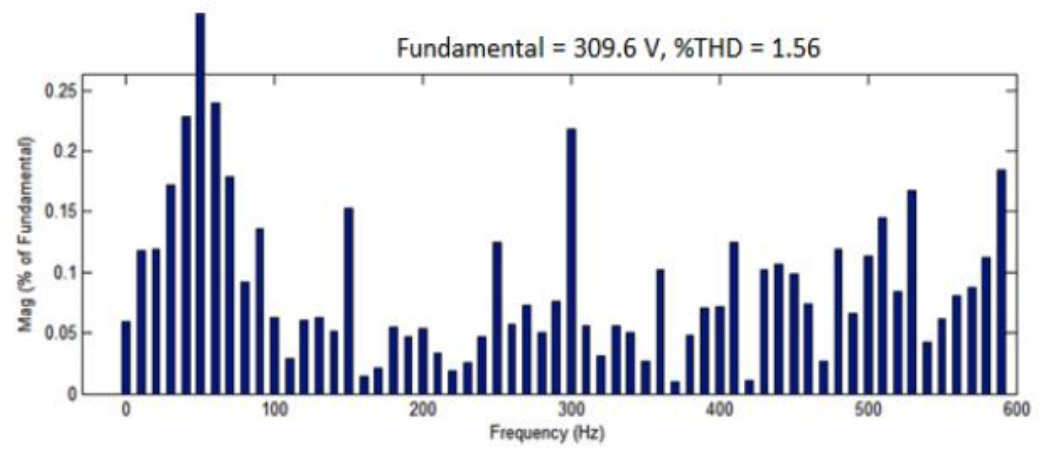

Fig 6 (a) Final or Inverter 2 output (b) output signal with THD

The final output voltage is almost equal to $220 \mathrm{~V}$ rms (309.6 V peak) with total harmonic distortion (THD) of $1.56 \%$ which is well below the IEC recommended value of $5 \%$.

iii. Transformer operating at $100 \mathrm{~Hz}$

Transformer Input

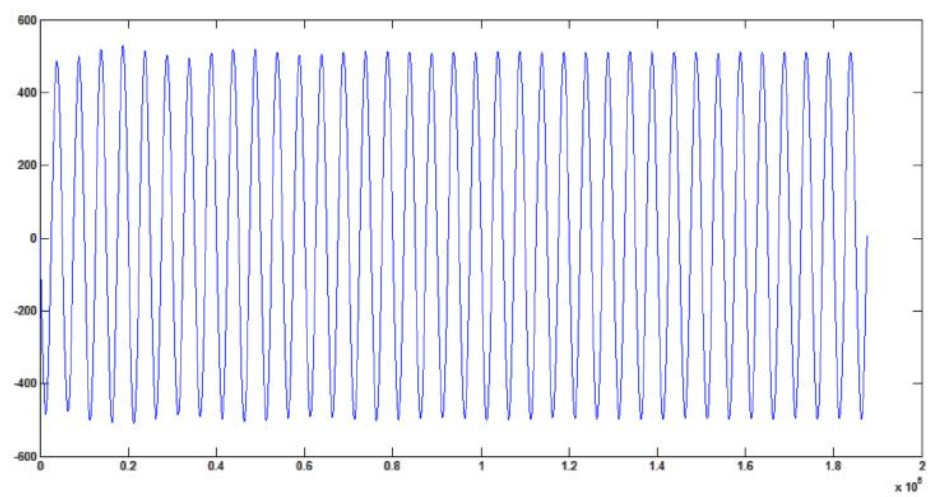

Fig.7 Transformer input or inverter 1 output

\section{Final Output}

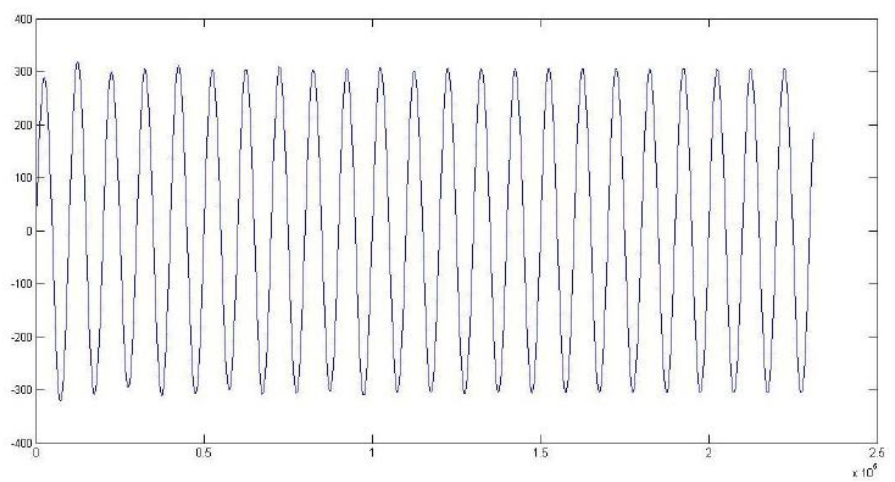




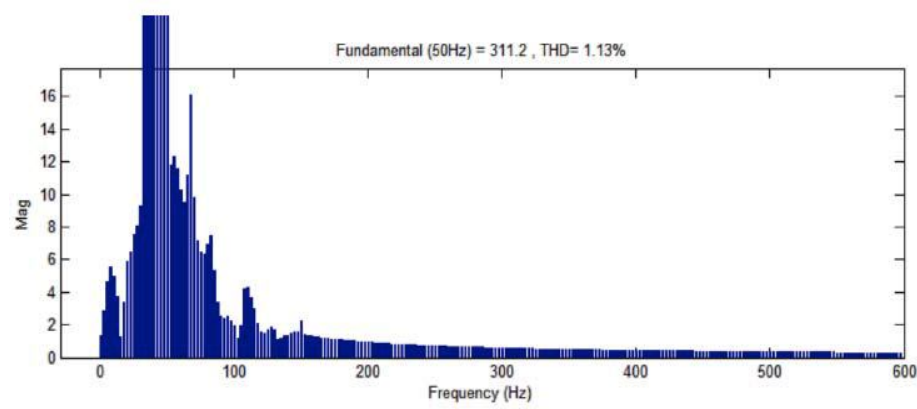

Fig.8 (a) Final or inverter 2 output (b) output signal with THD

The final output voltage is almost equal to $220 \mathrm{Vrms}$ (311.2 Vpeak) with total harmonic distortion (THDv) of $1.13 \%$ which is well below the IEC recommended value of $5 \%$. The THD at the load end is alleviated when the transformer is operated at $100 \mathrm{~Hz}$ instead of operating at the conventional frequency of 50 Hz. Over a specified interval of time, the transformer operation at both the frequencies is shown in figure 16 . There are 10 cycles in $50 \mathrm{~Hz}$ operation and 20 cycles in $100 \mathrm{~Hz}$ when checked between the points of plot, 2 and $3 * 10^{\wedge} 5$.

\section{HARDWARE IMPLEMENTATION}

The proposed model is made ready with the following components and tested at various frequencies for different loads.

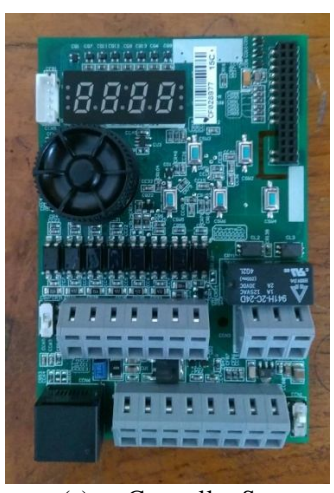

(a) Controller Set

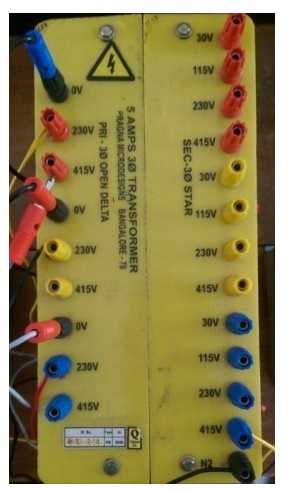

(c) Three Phase Transformer

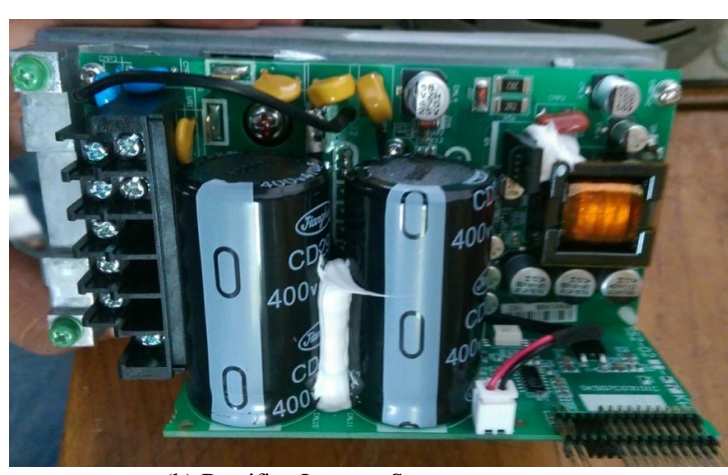

(b) Rectifier-Inverter Set

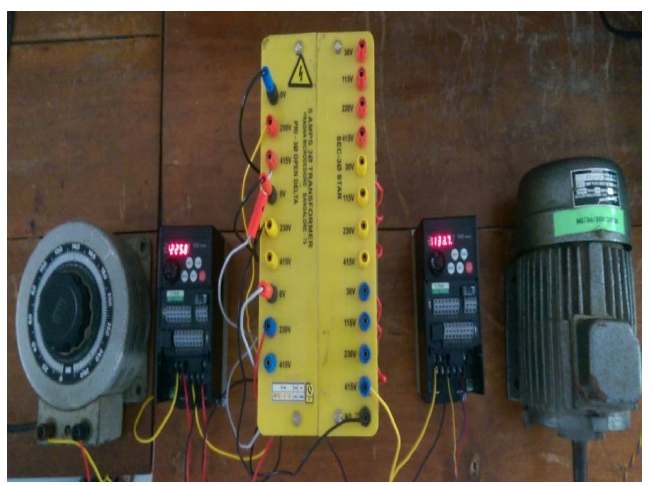

(d) SST under operation with Inductive Load 


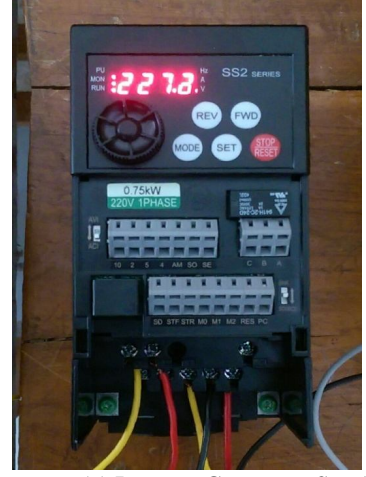

(e) Inverter Converter Set-1

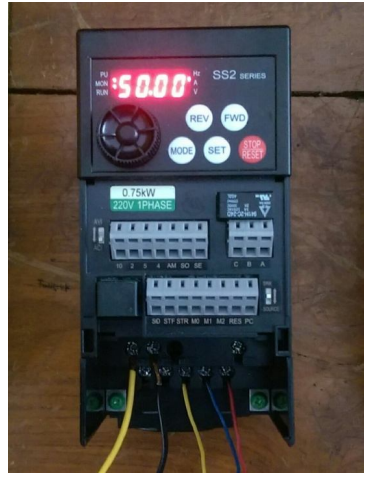

(f) Inverter Converter Set-2

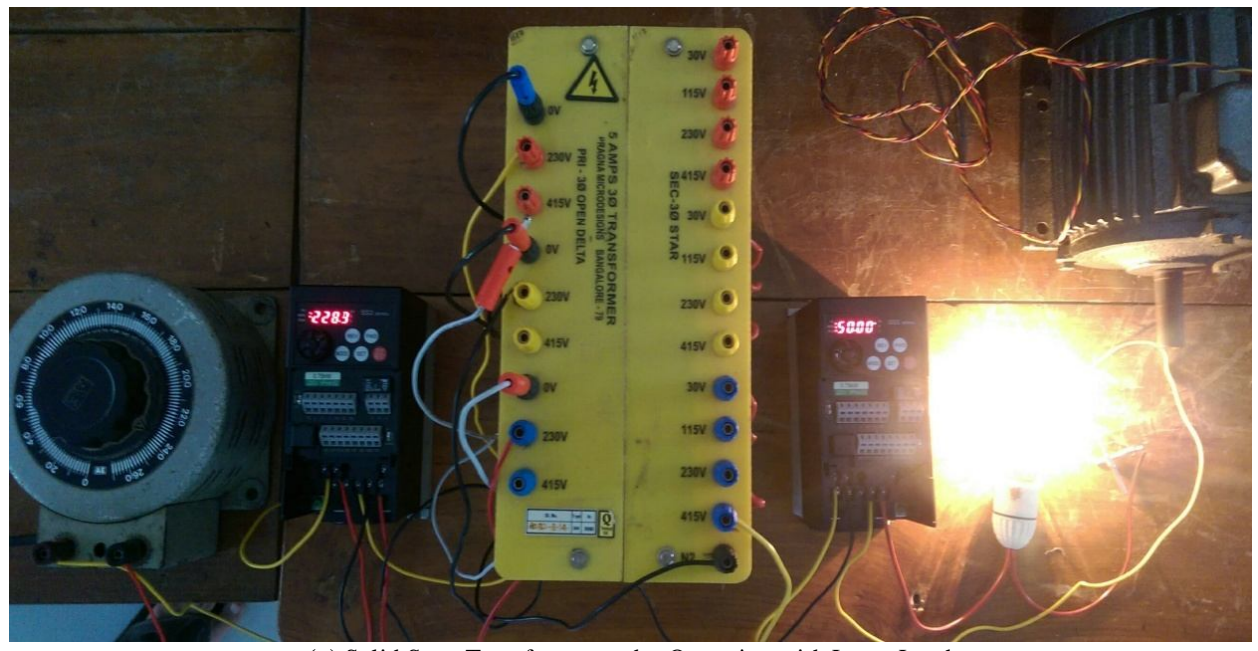

(g) Solid State Transformer under Operation with Lamp Load

Fig . 9 (a) to (g) Images of Hardware

Components used:

The following components, with specifications, are used in the organization of the SST model.

\begin{tabular}{|c|c|c|}
\hline S.No. & Component & Specification \\
\hline $\mathbf{1}$ & Rectifiers-1 \& 2 & $\begin{array}{c}\text { Diode Bridge of MEI make, KBPC-3510 (35A, 700V, } \\
\text { Vtt=1.1 V, PIV=1000 V) }\end{array}$ \\
& & $\begin{array}{c}\text { H-Bridge of IGBT: IGW15N120H3 of Infineon make, 1200 } \\
\text { V, 25 A }\end{array}$ \\
\hline $\mathbf{2}$ & Inverters- 1 \& 2 & 100 VA, 440/220 V \\
\hline $\mathbf{3}$ & Transformer & Power Quality Analyzer, Multimeter, Temperature sensor \\
\hline $\mathbf{4}$ & Measurement & Model: 3197 of HIKIO, Japan \\
\hline $\mathbf{4 . 1}$ & Power Quality Analyzer & Mini Infrared Gun of Fluke make (-18 to 275 0C), Model: 62 \\
\hline $\mathbf{4 . 2}$ & Temperature sensor & 100 W lamps, 65 W ceiling fan and 3 ph., 0.37 KW induction \\
\hline $\mathbf{5}$ & Loads &
\end{tabular}




\section{CONCLUSION}

Although SST adds extra cost factor, still it is preferred to use because of afore said advantages. At present, SSTs are being designed in a small quantity by Energy Systems Analyst Consortium (ESAC), ABB, Alstom and US Naval Academy.

Albeit the cost of the current generation of SSTs is not competitive with conventional passive transformers, SST is still attractive attributable to increase in the overall efficiency of the distribution system. An SST can increase power factor by reactive power control. In this way, the loss caused by reactive current is reduced, which can fully or partially compensate the increased loss by SST itself. The power efficiency of all three stages in an SST needs improvement which is possible with the following measures:

1) For the low voltage inverter, it might be advantageous to replace IGBTs with high voltage MOSFETs.

2) For the high voltage rectifier, the key issue is availability of new generation of power semiconductor devices.

Commercialization of SST is very low at present. However, it is expected to take-off within a few years. With the new generation semi-conductors, SSTs are being developed by a range of companies. It is likely to pick-up in a few years and will dominate the market with its integration in to DG and micro-grids.

Electricity networks are in the era of major transition from stable passive distribution networks with unidirectional electricity transportation to active distribution with bidirectional network. The extent of penetration of DG systems with the grid is increasing rapidly and thus its role is gaining prominence in electrical industry. With proper control over the distributed generation units, voltage sags are negated, reactive power flow is controlled.

Thus DG units with control measures for parameters are termed as Micro Grid (MG). From the reliability point of view, micro sources must be equipped with Power Electronic Interfaces (PEI) and latest sophisticated controls so as to provide the required flexibility to ensure operation as single aggregated system and to maintain quality.

\section{REFERENCES}

[1]. Xu She, Alex Huang, "Solid State Transformer in the Future Smart Electrical System", IEEE- 978-1-4799-13039/13.

[2]. Beldjajev Viktor1, Roasto Indrek2, Lehtla Tõnu3, 1-3Tallinn University of Technology "Intelligent Transformer: Possibilities and Challenges", Scientific Journal of Riga Technical University, Power and Electrical Engineering 2011.

[3]. X.u She, R.Burgos, G.Y.Wang, F.Wang, and A.Q.Huang, "Review of solid state transformer in the distribution system: from components to Field application," in Proc.IEEE.ECCE, 2012.

[4]. Alex Huang, Xu She, Xunwei Yu, Fei Wang, and Gangyao Wang, "Next Generation Power Distribution System Architecture: The Future Renewable Electric Energy Delivery and Management (FREEDM) System", ISBN: 9781-61208-259-2.

[5]. Xu She, Member, IEEE, Alex Q. Huang, Fellow, IEEE, and Rolando Burgos, Member, IEEE "Review of SolidState Transformer Technologies and Their Application in Power Distribution Systems" 2168-6777- 2013 IEEE.

[6]. Dorn, J. , Gambach, H. , Retzmann, D. , " HVDC transmission technology for sustainable power supply ”, Systems, Signals and Devices (SSD), 2012 9th International Multi-Conference , ISBN:978-1-4673-1589. 